\title{
Relação pessoa-ambiente: caminhos para uma vida sustentável
}

Person-environment relationship: paths to a sustainable life

\section{Relation personne-environnement: trajectoires á l'egard mode de vie durable}

\author{
La persona-ambiente: caminos para la vida sostenible
}

\author{
Elisa Ferrari Justulin Zacarias ${ }^{1}$ \\ Maria Inês Gasparetto Higuchi ${ }^{1}$ \\ Recebido em 29/10/2016; revisado e aprovado em 19/04/2017; aceito em 26/04/2017 \\ DOI: http://dx.doi.org/10.20435/inter.v18i3.1431
}

\begin{abstract}
Resumo: A ideia do comportamento sustentável emerge diante de um cenário de crise ambiental como uma possível solução em busca da reversão desse quadro. Entretanto há dificuldades em efetivar esse novo modo de pensar e agir, uma vez que o comportamento humano é alimentado por uma matriz complexa de filtros. Por essa razão, compreender a relação pessoa-ambiente pode fornecer instrumentos para superar esse impasse.
\end{abstract}

Palavras-chave: crise ambiental; comportamento; sustentabilidade.

Abstract: The idea of sustainable behavior, emerges in in a context of environmental crisis as a possible solution looking for a reversal of this crisis. However, there are profound difficulties in changing this new way of thinking and acting, since a complex array of filters powers human behavior towards the environment. For this reason, understanding the person-environment relationship can provide tools to overcome this impasse.

Key words: environmental crisis; behavior; sustainability.

Résumé: L'idée d'un comportement durable émerge avant un scénario de crise environnementale comme une solution possible recherchant le contraire de ses crises. Quoi qu'il en soit, ils ont des difficultés profondes en changeant cette nouvelle façon de penser et agir, depuis que le complexe ensemble de ses filtres puissants une fois que le comportement humain s' adapte á l'environnement. Pour cette raison, comprenant la relation personne-environnement, peut fournir des instrumentos pour vaincre cette impasse.

Mots-clés: crises d'environnement; comportement; supportabilité.

Resumen: La idea de conducta sustentable surge ante un escenario de crisis ambiental como una posible salida en la búsqueda de una solución a esta situación. Sin embargo, existen dificultades en la realización de esta nueva forma de pensar y actuar, ya que el comportamiento humano es impulsado por un complejo conjunto de filtros. Por esta razón, la comprensión de la relación persona-ambiente puede proporcionar herramientas para superar esta problemática.

Palabras clave: crisis ambiental; comportamiento; sustentabilidad.

\section{INTRODUÇÃO}

O modo como as pessoas pensam e se relacionam com a natureza é resultado de uma construção histórica e social uma vez que as normas sociais modelam as atitudes e ações humanas que, por sua vez, alteram a natureza. As relações com a natureza se modificaram em forma e intensidade, ao longo da história da humanidade, em cujos primórdios ser caçador-coletor definia uma conexão intrínseca e de dependência com a natureza. Na atualidade, entretanto, o homem moderno se reconhece como desconectado da natureza, pensando-a como algo exterior a si e, portanto, passível de ser controlada, subjugada e explorada.

Como resultado da exploração exacerbada dos recursos naturais, temos os problemas ambientais. Estes têm se intensificado e, cada vez mais, suas consequências são notadas pelas

\footnotetext{
${ }^{1}$ Universidade Federal do Amazonas (UFAM), Manaus, Amazonas, Brasil.
} 
pessoas. Entre esses problemas, a mudança climática, a perda de biodiversidade, o derretimento das geleiras, a elevação do nível do mar, o acúmulo de resíduos sólidos, a poluição e a destruição das florestas constituem exemplos, frequentemente divulgados pela mídia (OSKAMP, 2000). Esses eventos revelam a necessidade de voltarmos o olhar para a relação pessoa-ambiente e sua repercussão no comportamento insustentável adotado em nossa sociedade.

A relação pessoa-ambiente parte do pressuposto de que, ao alterar o ambiente, o ser humano tem seu comportamento e experiência modificada pelo ambiente (GIFFORD, 2005). Devido a essa recursividade, o comportamento humano é responsável por grande parte dos problemas ambientais. Assim, é imperativo adotar comportamentos sustentáveis, para mitigar os efeitos da crise ambiental e vislumbrar a desejada sustentabilidade ambiental (NASCIMENTO, 2012; CAVALCANTI, 2012).

Adotar um modo de vida sustentável está, diretamente, ligado à mudança do modo de pensar e agir, no entanto estes não são fáceis de mudar. Stern (2011) aponta que essa alteração é tão difícil quanto modificar comportamentos relacionados à saúde, como exemplo, os que envolvem dieta. A Psicologia Ambiental tem contribuído nesse fenômeno uma vez que o comportamento humano é uma premissa básica para a desejada mudança na relação pessoa-ambiente (AMERICAN PSYCHOLOGICAL ASSOCIATION [APA], 2009; STOKOLS et al., 2009; CORRAL-VERDUGO, 2010; LEMOS; HIGUCHI, 2011; LARSON et al., 2015). Com base nesses pressupostos, o presente ensaio teórico problematiza a crise ambiental e comportamentos sustentáveis como temáticas inerentes à relação pessoa-ambiente que vislumbre o equilíbrio entre demandas sociais e capacidade de suporte dos ecossistemas.

\section{A CRISE AMBIENTAL EM FUNÇÃO DE RELAÇÕES PESSOA-AMBIENTE INSUSTENTÁVEIS}

Para apreender a crise ambiental, na qual a sociedade contemporânea está inserida, é necessário reconhecer que os ecossistemas naturais (hidrosfera, litosfera, atmosfera e biosfera) são modelos de sustentabilidade, cuja dinâmica se mantém como parte de sua longa história de formação. No entanto alguns estudiosos consideram a existência de uma nova esfera, a tecnosfera (MILLER JR., 2007), que diz respeito à interrelação entre sistema natural e sistema humano na sua rubrica de socioeconomia. Quando o homo sapiens (há 190 mil anos a.C.) começa a produzir suas próprias ferramentas, fabricar armas, praticar a agricultura e conhecer o mundo que o rodeia, ele passa a edificar cidades, pois tem condições de se proteger e cultivar elementos. Esses acontecimentos marcaram a evolução cultural do ser humano e a dissociação crescente com a natureza, caracterizando o início e desenvolvimento da "civilização".

No decorrer dos séculos, os seres humanos foram aperfeiçoando suas técnicas e equipamentos, até o ponto que culminou na Revolução Industrial (século XIX). Com a grande explosão urbana europeia, decorrente da industrialização, muitos teóricos - dentre eles Karl Marx, Èmile Durkheim e Max Weber - discorreram acerca da mudança radical dos estilos de vida e das relações sociais. As novas forças econômicas, as possibilidades propiciadas pelo desenvolvimento do sistema de transporte e comunicação e a limitação de espaço dentro das cidades propiciaram o desenvolvimento de um novo modelo de organização das sociedades (GLASSER, 2016).

Um debate acirrado passa a existir entre ambientalistas e pessoas preocupadas com o cenário desenvolvimentista. O modo de pensar e agir presente na sociedade atual é posto em 
xeque, e uma corrente educacional se empenha nesse sentido. Por exemplo, em 2007 a ambientalista norte-americana Annie Leonard produz um documentário de 21 minutos sobre "A história das coisas", que aborda, de forma dinâmica, as cinco etapas da economia de materiais: extração, produção, distribuição, consumo e tratamento do lixo. O roteiro no documentário tenta mostrar que todas essas etapas geram impactos socioambientais nas mais diversas localidades e em diversos âmbitos. Entre os vários informes, Leonard mostra que, em um período de seis meses, 99\% dos produtos adquiridos são descartados. Isso remete ao processo de extração da matéria prima, na energia empregada na fase de produção, bem como nos insumos químicos e poluição gerada nessa etapa e, em última instância, o descarte do produto, o que resulta no aumento do lixo produzido. Esse processo de sensibilização já é bastante recorrente, mas ainda está distante de uma verdadeira e profunda mudança do pensar e agir sustentável.

O comportamento de consumo atual é reconhecidamente insustentável para o planeta, de tal forma que é imperativo promover ações de maior equilíbrio entre as demandas sociais e a capacidade de suporte ambiental em todas as sociedades indistintamente. Pensar o bem-estar humano a longo prazo implica, necessariamente, reavaliar o modo de atender as demandas sociais, buscando equilíbrio com o ecossistema (ZANIRATO; ROTONDARO, 2016). Pouco se tem mudado, no entanto.

É de consenso na literatura que a Revolução Industrial suscitou um processo acelerado dos problemas sociais e ambientais. Com esse desencadeamento pernicioso do modo de pensar e agir da sociedade, tem-se um duplo desafio: alcançar um progresso social e econômico que viabilize a qualidade de vida e bem-estar a todos os habitantes do planeta e, concomitantemente, resolver o cenário de crise ambiental global oriunda do modelo de desenvolvimento socioeconômico (CASTRO, 2002).

Somente a partir da segunda metade do século XX, que as preocupações em torno da temática ambiental se evidenciam. Na década de 1950, a humanidade vivenciava os efeitos da poluição nuclear, o que serviu como um alerta aos "passageiros da nave espacial Terra (SACHS apud BRESSER-PEREIRA, 2013, p. 364). Em outras palavras, as ações que desencadeiam os problemas ambientais afetam lugares distantes de onde estas ocorreram e, em certos casos, isso é capaz de assolar todo o planeta.

Em 1962, Rachel Carson publicava Silent Spring. Neste livro, a autora denuncia o emprego de inseticidas e pesticidas químicos em plantações. Carson observou, que essas aplicações não só eram capazes de matar as pragas - como insetos, ervas daninhas e fungos - porém, fazia o mesmo com outras espécies animais. Além disso, esses produtos químicos atingiam todo o ecossistema: solo, água, fauna e flora e, ao adentrar na cadeia alimentar, alcançaria os humanos. A publicação desse livro causou grande impacto e mobilizou a mídia, governos e, em especial, os movimentos ambientalistas, que ganharam mais força e visibilidade. No ano de 1968, os países escandinavos foram acometidos por chuvas ácidas. Por essa razão, a Suécia propôs ao Conselho Econômico e Social das Nações Unidas (ECOSOC) a efetivação de uma conferência mundial, visando a um acordo internacional para promover a redução da emissão de gases causadores da chuva ácida.

Nas últimas décadas, o processo de mudança climática e os eventos extremos compõem uma agenda de temor à nossa existência no planeta. Além disso, outros problemas ambientais, tais como a extinção da biodiversidade, a poluição atmosférica, a redução da camada de ozônio, a escassez de recursos hídricos e a grande concentração populacional no meio urbano são ingredientes de preocupação da sociedade (OSKAMP, 2000; CLEMENT; HIGUCHI, 2006; NASCIMENTO, 2012). 
Preocupar-se é um modo de pensar necessário e urgente, mas não é suficiente para um agir que culmine numa vida sustentável. É imprescindível uma transformação da relação pessoa-ambiente nos mais diversos segmentos para um enfrentamento efetivo (CAVALCANTE; ELALI, 2011). O ideal da apreensão de comportamentos sustentáveis não reside apenas no empenho de uma gestão pública ou organizacional, embora tenha sua parte na responsabilidade da formação de uma agenda sustentável, mas também, e sobretudo, no empenho de cada habitante deste planeta. Uma conduta sustentável requer mudanças básicas na relação de cada indivíduo para com o ambiente indistintamente (OSKAMP, 2000).

\section{TRANSFORMAÇÕES PARA UMA RELAÇÃO PESSOA-AMBIENTE SUSTENTÁVEL}

Com o intuito de abarcar a completude da relação pessoa-ambiente, é imprescindível afastar-se das proposições teóricas fundamentadas em dualidade (sujeito-objeto, material-simbólico, por exemplo). Afinal, essas teorias ocultam o fato de que cada indivíduo se caracteriza por sua unicidade e por ser produto das relações sociais que instaura (HIGUCHI; KUHNEN, 2008). Desse modo, ao refletir sobre a ligação estabelecida entre seres humanos e meio ambiente, perpassamos, necessariamente, pelos processos socioculturais além das características eminentemente pessoais. Porquanto, de acordo com Tuan (2012), a cultura tem forte impacto na relação pessoa-ambiente. Nesse sentido, Kuhnen, Improta e Silveira (2009) enfatizam que não se trata de uma crise ambiental, mas de uma crise das pessoas-nos-ambientes, isto é, da maneira como as pessoas se relacionam com o ambiente a sua volta. Tuan (2012), corrobora com esse pensar na medida em que considera os problemas ambientais como problemas humanos, os quais são desencadeados pelos valores e atitudes de cada pessoa.

Os processos socioculturais podem ser pensados como um sistema polissêmico, no qual concorrem aspectos cognitivos (refere-se a todo conhecimento que alguém deve dominar para atuar na sociedade), estruturais (conjunto de símbolos elaborados e acumulados pela mente humana) e simbólicos (totalidade de mecanismos empregados para gerir o comportamento). Assim, estudar tais processos, ou simplesmente cultura, é analisar um código de símbolos, compartilhados pelo grupo, ainda que nenhum indivíduo seja capaz de apreender plenamente o seu sistema cultural, pois compreendê-lo significa conhecer todas as categorias desenvolvidas por seus membros (LARAIA, 1986).

O pertencimento a uma determinada cultura configura aspecto de nossa identidade que não é necessariamente imutável. Hall (2000) afirma que as sociedades modernas são, por definição, sociedades em constante mudança, o que causa implicações na cultura e, em última instância, na identidade das pessoas - por essa razão, a identidade não é concebida com algo fixo nem estável, ela flutua livremente. Em vista disso, pode-se inferir que, ao agir sobre o ambiente, o ser humano o modifica de forma dinâmica e circunstancial. Entretanto apenas os aspectos socioculturais não são absolutos e exclusivos, uma vez que aspectos do meio ambiente também atuam sobre o comportamento das pessoas (HIGUCHI; CALEGARE; FREITAS, 2013). Por conseguinte refletir sobre todos esses aspectos se torna vital para compreender não só a crise ambiental, mas também a proposta de sustentabilidade como elemento de salvação.

Muitos estudos nos têm alertado sobre a necessidade de se compreender as percepções ambientais que subsidiam a relação pessoa-ambiente (CORRAL-VERDUGO; PINHEIRO, 2004; KUHNEN; HIGUCHI, 2011; TUAN, 2012). Por essa razão, ao compreendermos tais elementos 
subjetivos, que acabam também por tecer a malha cultural, é possível aprofundarmos aspectos mais substanciais tanto da crise ambiental quanto da possibilidade de enveredarmos para um comportamento sustentável.

Devido à sua função de interpretação e construção de significados, a percepção ambiental exerce papel relevante nos processos de apropriação e uso social dos espaços. As dimensões psicossociais presentes no conceito de percepção ambiental envolvem a cognição - processo pelo qual as pessoas criam imagens mentais; afeto em relação ao ambiente, o que conduz ao apego; e, por fim, as preferências relacionadas ao ambiente, que possibilitam identificar o nível de atratividade de seus elementos constituintes para as pessoas, o que facilita o entendimento dos aspectos capazes de tornar um lugar atrativo ou repulsivo (KUHNEN; HIGUCHI, 2011).

Nesse sentido, podemos considerar que a percepção ambiental é uma categoria analítica que nos permite verificar como as pessoas vivenciam sua realidade e, a partir dessa vivência, como percebem a formação do mundo à sua volta, incluindo-se ou excluindo-se dele. Tal postura cognitiva e afetiva possibilita desenvolver filtros, que estabelecem diferentes ligações no âmbito em que estão imersas. No decorrer desse processo de filtragem e seleção, torna-se possível a estruturação e identificação do ambiente (KUHNEN; HIGUCHI, 2011), bem como as relações que se dão entre pessoa-ambiente.

No percorrer do processo de interação entre pessoa-ambiente, o espaço físico transforma-se em um espaço significativo para esse processo. O significado atribuído ao ambiente é produto do impacto emocional, que o meio natural produz em cada um de nós, e isso é determinado pelo tipo de relação que o indivíduo pode estabelecer com ele (CORRALIZA, 2002). De tal sorte, a paisagem da floresta, por exemplo, pode ser muito atrativa para uma pessoa com espírito aventureiro, mas, para alguém que convive nesse ambiente, torna-se habitual e até enfadonha.

A percepção ambiental possibilita ainda verificar aspectos emocionais designados como apego ao lugar, que se refere à ligação - afetiva ou cultural - que o indivíduo mantém com o ambiente físico (ELALI; MEDEIROS, 2011). Estudos relativos a essa temática, abordam três dimensões: funcional (considera a capacidade de o espaço físico despertar emoções - atração, medo, bem-estar); simbólica (diz respeito ao arcabouço simbólico que cada indivíduo carrega, e que estrutura relação pessoa-ambiente) e, por fim, a relacional (refere-se à dinâmica das relações sociais estabelecidas, concomitante às características do ambiente em que elas se efetivam).

Dessa forma, podemos pressupor que as relações humanas são afetadas pelo espaço físico, da mesma forma que o espaço físico modela tais relações produzindo um complexo fenômeno de interações (TORVISCO, 2002). Essa recursividade fornece perspectivas complementares sobre o caráter da percepção e consequente atitude ambiental (TUAN, 2012). Nesse bojo, incluem aspectos relativos ao entendimento do entorno e respectivos aspectos éticos envolvidos na relação pessoa-ambiente. Lemos e Higuchi (2011) postulam que o modo como as pessoas compreendem e atribuem significados ao entorno físico e sociocultural manifesta-se em atitudes singulares de compromisso ambiental, produzindo o que as autoras chamam de ethos socioambiental.

O debate em torno da crise ambiental implica, pois, pensar não apenas nos grandes eventos planetários e convenções políticas, mas sobretudo nas bases do comportamento das pessoas, pois, direta ou indiretamente, nossas ações contribuem para acelerar a degradação ambiental e suscita enfrentamentos específicos (PATO; CAMPOS, 2011). Thogersen (2014) ressalta que nossa forma de vida (conduta, comportamento), seja no âmbito individual ou familiar, não é sustentável. Logo, contribui de forma significativa para o impacto ambiental. 
Por essa razão, Lemos e Higuchi (2011) ponderam sobre os parâmetros de ação da humanidade elaborados pelas convenções internacionais, como um instrumento que visa aumentar a responsabilidade e o compromisso da sociedade para com o meio ambiente. Entretanto, como já posto anteriormente, o acesso à informação não é suficiente para suscitar mudanças na relação pessoa-ambiente; é preciso sensibilizar e refletir sobre o quanto nossas ações e escolhas cotidianas contribuem para a degradação do meio ambiente.

Nesse sentido, enfatizar a relação pessoa-ambiente, embasada numa mudança dos padrões de consumo, possibilita fortalecer a ação política dos cidadãos; ademais, estimula o desenvolvimento de novas estratégias, como o consumo sustentável. A ideia que fundamenta esse conceito vai muito além das inovações promovidas pela tecnologia e mudanças nos padrões de consumo, destaca o papel das ações coletivas e mudanças nas áreas política, econômica e institucional, com o intuito de alcançar a sustentabilidade (BRASIL, 2005). Em suma, podemos considerar que o princípio do comportamento sustentável se assenta no reconhecimento da nossa responsabilidade em relação às outras pessoas e ao meio ambiente, na justiça ambiental (HERCULANO, 2002; LEAL, 2013) e no equilíbrio das demandas sociais respeitando a capacidade de suporte dos ecossistemas.

Captar as peculiaridades relacionadas ao comportamento humano (lembrando que esse é moldado tanto pelos aspectos físicos do ambiente, quanto pelos aspectos psicossociais e pela cultura, em cuja miscigenação, constituirá sua identidade e, portanto, impactará sobre sua percepção ambiental e apego ao lugar), auxiliará na elaboração de ações estratégicas mais eficientes e desenvolvimento de uma política ambiental que esteja em consonância com a realidade de nosso país. Uma nova relação pessoa-ambiente pode estar emergindo a partir de modos sustentáveis, ainda que lentamente.

Os modos vigentes, no entanto, terão que ser revistos e ressignificados, pois segundo Thogersen (2014), os hábitos enraizados tornam-se difíceis de alterar, pela falta de motivação para mudança. Para efetivar uma conduta sustentável, é indispensável conhecer como as pessoas agem e pensam, quais as motivações, expectativas, entendimentos e prioridades. Alcançar esse conjunto de fatores possibilita compreender as implicações do meio ambiente sobre o comportamento das pessoas, e vice-versa. De posse desse saber, é possível elaborar programas e intervenções interdisciplinares para efetivar o enfrentamento à crise ambiental.

Diante da crise ambiental, a proposta da apreensão efetiva de comportamentos sustentáveis emerge como rubrica de uma nova relação pessoa-ambiente. O comportamento sustentável tem origens na discussão da chamada sustentabilidade, porém se distingue pelo fato de ser situada em práticas efetivas de cada indivíduo.

No âmbito dessa discussão, emerge, dentro da Psicologia Ambiental, o construto de conduta sustentável, no qual está latente a busca pelo equilíbrio ecológico por meio do cuidado com o ambiente e do bem-estar humano. Corral-Verdugo e Pinheiro (2004) postulam que a conduta sustentável se manifesta pelo conjunto de ações efetivas, deliberadas e antecipadas capazes de promover a preservação de recursos naturais e culturais (CORRAL-VERDUGO; PINHEIRO, 2004; CORRAL-VERDUGO et al., 2009).

Considerando que o conceito de conduta sustentável ressalta a necessidade de cuidar ao ambiente físico e social através de ações voltadas a sanar essa lacuna, alguns fatores psicológicos são apontados como indicadores desse tipo de ação, dentre eles o altruísmo, a austeridade e a deliberação. $O$ altruísmo pode ser compreendido como a tendência a se preocupar e atuar em 
favor do outro (tanto inter como intrageracional) por essa razão, é apontado como característica necessária para alcançar uma vida sustentável. A austeridade ou frugalidade designa uma característica da conduta sustentável devido à adoção de um estilo de vida caracterizado pela redução do consumo. Por fim, a deliberação pode ser definida como uma dimensão cognitiva capaz de orientar o comportamento humano, para que tenha o propósito de cuidar do ambiente e fomentar o bem-estar de todos os seres vivos no seu entorno (CORRAL-VERDUGO; PINHEIRO, 2004; CORRAL-VERDUGO et al., 2009).

Apesar das macrodiscussões que o termo sustentabilidade discorre, pensar o comportamento sustentável requer um foco no indivíduo, mesmo que inserido na coletividade em suas rubricas mais diversas. De acordo com Thogersen (2014), a atividade humana (tanto no âmbito individual, quanto coletivo), é responsável por uma parcela significativa nos impactos ambientais. A ideia de comportamentos sustentáveis, ou mais especificamente, do consumo sustentável, emerge, nesse sentido, com o intuito de adquirir apenas o necessário; prolongar, ao máximo, a vida útil dos produtos - contrariando, assim, o princípio de obsolescência perceptiva - e, principalmente, depreender que nossas escolhas acarretam impactos ambientais e sociais, assim, consumir de forma sustentável pode reduzir as pressões no planeta.

\section{CONSIDERAÇÕES FINAIS}

A humanidade tem se questionado acerca das condições necessárias para garantir seu bem-estar social e equilíbrio ecológico. As sucessivas indagações e a busca sistemática por respostas têm dado conta de uma crise ambiental manifestada pelo desenfreado crescimento populacional, pelas insustentáveis demandas por moradia, alimento e energia, pelo exacerbado consumo, pela poluição dos rios, ar e terra, entre tantos outros. Cada indivíduo é chamado a rever comportamentos que, direta ou indiretamente, provocam o desequilíbrio da vida nesse planeta, a partir de sua localização imediata e como são reverberados em instâncias mediatas e na rede de conexões socioambientais.

Para que a desejada adesão efetiva à comportamentos mais sustentáveis seja alcançada, temos que nos aprofundar na compreensão do comportamento humano. Nesse sentido, examinar e (re) orientar as ações humanas para que essa forma de pensar e agir se torne efetiva e presente no cotidiano dos indivíduos e da coletividade. Investir em estudos e propostas educativas centradas na relação pessoa-ambiente, é um caminho profícuo para a necessária sustentabilidade.

\section{REFERÊNCIAS}

AMERICAN PSYCHOLOGICAL ASSOCIATION (APA). Psychology \& Global Climate Change: addressing multifaceted phenomenon and set of challenges. A Report of the American Psychological Association. New York, 2009.

BRASIL. Ministério Meio Ambiente (MMA); Ministério da Educação (MEC). Consumo sustentável: manual de educação. Brasília: Consumers International/MMA/MEC/IDEC, 2005. Disponível em: <http://portal. mec.gov.br/dmdocuments/publicacao8.pdf>. Acesso em: 3 jun. 2016.

BRESSER-PEREIRA, Luiz Carlos. Ignacy Sachs e a nave espacial Terra. Revista de Economia Política, São Paulo, v. 33, n. 2, p. 360-66, abr./jun. 2013. Disponível em: <http://www.scielo.br/scielo.php?script=sci_ar ttext\&pid=S0101-31572013000200010>. Acesso em: 25 abr. 2016.

CASTRO, Ricardo de. Educación ambiental. In: ARAGONÉS, Juan Ignacio; AMÉRIGO, María (Org.). Psicología Ambiental. Madrid: Ediciones Pirámides, 2002. p. 357-79. 
CAVALCANTE, Sylvia; ELALI, Gleice Azambuja. Temas básicos em Psicologia Ambiental. Petrópolis, RJ: Vozes, 2011.

CAVALCANTI, Clóvis. Sustentabilidade: mantra ou escolha moral? Uma abordagem ecológico-econômica. Estudos Avançados, São Paulo, v. 26, n. 74, p. 35-50, 2012. Disponível em: <http://www.scielo.br/scielo. php?script=sci_arttext\&pid=S0103-40142012000100004>. Acesso em: 24 abr. 2016.

CLEMENT, Charles R.; HIGUCHI, Niro. A floresta amazônica e o futuro do Brasil. Ciência e Cultura, São Paulo, v. 58, n. 3, p. 44-9, jul./set. 2006. Disponível em: <http://cienciaecultura.bvs.br/scielo.php?pid=S000967252006000300018\&script=sci_arttext>. Acesso em: 18 abr. 2017.

CORRAL-VERDUGO, Victor. Psicología de la sustentabilidad. Un análisis de lo que nos hace pro ecológicos y pro sociales. México: Trillas, 2010.

CORRAL-VERDUGO, V. et al. Orientación a la sostenibilidad como base para el comportamiento pro-social y pro-ecológico. Medio Ambiente y Comportamiento Humano, v. 10, n. 3, p. 195-215, 2009. Disponível em: <https://mach.webs.ull.es/PDFS/Vol10_3/Vol10_3_b.pdf>. Acesso em: 24 abr. 2017.

CORRAL-VERDUGO, V.; PINHEIRO, J. Q. Aproximaciones al estudio de la conducta sustentable. Medio ambiente y comportamiento humano, v. 5, n. 1, p. 1-26, 2004. Disponível em: <https://sistemamid.com/ panel/uploads/biblioteca/2014-09-30_10-57-10111187.pdf>. Acesso em: 20 abr. 2017

CORRALIZA, Jose Antonio. Emoción y ambiente. In: ARAGONÉS, Juan Ignacio; AMÉRIGO, María (Org.). Psicología ambiental. Madrid: Ediciones Pirámides, 2002. p. 59-76.

ELALI, Gleice Azambuja; MEDEIROS, Samia Thaís Feijó de. Apego ao lugar. In: CAVALCANTE, Sylvia; ELALI, Gleice Azambuja. Temas básicos em Psicologia Ambiental. Petrópolis, RJ: Vozes, 2011. p. 53-62.

GIFFORD, Robert. O papel da Psicologia Ambiental na formação da Política Ambiental e na construção do futuro. Psicologia USP, v. 16, n. 1-2, p. 237-47, 2005. Disponível em: <http://www.revistas.usp.br/ psicousp/article/viewFile/41854/45522>. Acesso em: 18 abr. 2017

GLASSER, Harold. Visions of Sustainability. Sustainability: The Journal of Record, v. 9, n. 2, p. 56-64, abr. 2016. Disponível em: <http://online.liebertpub.com/doi/pdf/10.1089/SUS.2016.29044>. Acesso em: 24 abr. 2016.

HALL, Stuart. A identidade cultural na pós-modernidade. Rio de Janeiro: DP\&A, 2000.

HERCULANO, Selene. Riscos e desigualdade social: a temática da Justiça Ambiental e sua construção no Brasil. In: ENCONTRO DA ANPPAS, 1., 2002, Indaiatuba, SP. Disponível em: <http://www.anppas.org.br/ encontro_anual/encontro1/gt/teoria_meio_ambiente/Selene\%20Herculano.pdf>.

HIGUCHI, Maria Inês Gasparetto; KUHNEN, Ariane. Percepção e representação ambiental - métodos e técnicas de pesquisa para a Educação Ambiental. In: PINHEIRO, José de Queiroz; GUNTHER, Hartmut (Org.). Métodos de pesquisa nos estudos pessoa-ambiente. São Paulo: Casa do Psicólogo, 2008. p. 181-215.

HIGUCHI, Maria Inês Gasparetto; CALEGARE, Marcelo Gustavo Aguilar; FREITAS, Camila Carla. Socialidade e espacialidade nas comunidades de Unidades de Conservação no Amazonas. In: HIGUCHI, Maria Inês Gasparetto; FREITAS, Camila Carla; HIGUCHI, Niro. Morar e viver em Unidades de Conservação no Amazonas: considerações socioambientais para os planos de manejo. Manaus: [s.n.], 2013. p. 23-62.

KUHNEN, Ariane; HIGUCHI, Maria Inês Gasparetto. Percepção ambiental. In: CAVALCANTE, Sylvia; ELALI, Gleice Azambuja. Temas básicos em Psicologia Ambiental. Petrópolis, RJ: Vozes, 2011. p. 250-66.

KUHNEN, Ariane; IMPROTA, Rafaella Lenoir; SILVEIRA, Scheila Machado da. Comportamento humano e recursos naturais: qualidade e disponibilidade da água avaliadas pelos usuários. Psicologia: Teoria e Pesquisa, Brasília, v. 25, n. 3, p. 453-60, jul./set. 2009. Disponível em: <http://www.scielo.br/scielo. php?script=sci_arttext\&pid=S0102-37722009000300021>. Acesso em: 28 abr. 2016.

LARAIA, Roque de Barros. Cultura: um conceito antropológico. Rio de Janeiro: Zahar, 1986.

LARSON, L. R. et al. Understanding the multi-dimensional structure of pro-environmental behavior. Journal of Environmental Psychology, v. 43, p. 112-24, set. 2015. Disponível em: <http://www.sciencedirect.com/

INTERAÇÕES, Campo Grande, MS, v. 18, n. 3, p. 121-129x, jul./set. 2017. 
science/article/pii/S0272494415300177>. Acesso em: 24 abr. 2017.

LEAL, Giuliana Franco. Justiça ambiental, conflitos latentes e externalizados: estudo de caso de pescadores artesanais do Norte Fluminense. Ambiente \& Sociedade, v. 16, n. 4, p. 83-102, 2013. Disponível em: $<$ http://www.scielo.br/scielo.php?pid=S1414-753X2013000400006\&script=sci_abstract\&tIng=pt $>$. Acesso em: 20 abr. 2017.

LEMOS, Sônia Maria; HIGUCHI, Maria Inês Gasparetto. Compromisso socioambiental e vulnerabilidade. Ambiente \& Sociedade, Campinas, SP, v. 14, n. 2, p. 123-38, jul./dez. 2011. Disponível em: <http://www. scielo.br/scielo.php?script=sci_arttext\&pid=S1414-753X2011000200009>. Acesso em: 2 maio 2016.

MILLER JR., G. Tyler. Ciência Ambiental. Tradução da 11. ed. Norte-Americana. [S.I.]: Cencage Learning, 2007.

NASCIMENTO, Elimar Pinheiro do. Trajetória da sustentabilidade: do ambiental ao social, do social ao econômico. Estudos Avançados, São Paulo, v. 26, n.74, p. 51-64, 2012. Disponível em: <http://www.scielo. br/pdf/ea/v26n74/a05v26n74.pdf>. Acesso em: 20 mar. 2016.

OSKAMP, Stuart. Psychological contributions to achieving an ecologically sustainable future for humanity. Journal of Social Issues, v. 56, n. 3, p. 373-90, 2000. Disponível em: <https://web.stanford. edu/ kcarmel/CC_BehavChange_Course/readings/Additional\%20Resources/J\%20Soc\%20lssues\%202000/ oskamp_2000_2_generalobstacles_c.pdf>. Acesso em: 10 jun. 2016.

PATO, Claudia Márcia Lyra; CAMPOS, Camila Bolzan de. Comportamento ecológico. In: CAVALCANTE, Sylvia; ELALI, Gleice Azambuja. Temas básicos em Psicologia Ambiental. Petrópolis, RJ: Vozes, 2011. p. 122-43.

STERN, Paul. Contributions of Psychology to limiting climate change. American Psychologist, v. 66, n. 4, p. 303-14, maio/jun. 2011. Disponível em: <http://psycnet-apa-org.ez44.periodicos.capes.gov.br/journals/ amp/66/4/303/>. Acesso em: 10 maio 2016.

STOKOLS, Daniel; MISRA, Shalini; RUNNERSTROM, Miryha Gould; HIPP, J. Aaron. Psychology in an Age of Ecological Crisis: From Personal Angst to Collective Action. American Psychologist, v. 64, n. 3, p. 181-93, abr. 2009. Disponível em: $<$ http://psycnet.apa.org/?fa=main.doiLanding\&doi=10.1037/a0014717>. Acesso em: 08 maio 2016.

THOGERSEN, John. Unsustainable consumption: basic causes and implications for policy. European Psychologist, n. 19, p. 84-95, jan. 2014. Disponível em: <http://econtent.hogrefe.com/doi/ abs/10.1027/1016-9040/a000176>. Acesso em: 6 jun. 2016.

TORVISCO, Juan Martínez. Espacio personal y ecologia del pequeño grupo. In: ARAGONÉS, Juan Ignacio; AMÉRIGO, María (Org.). Psicología Ambiental. Madrid: Ediciones Pirámides, 2002. p. 102-22.

TUAN, Yi Fu. Topofilia - um estudo de percepção, atitudes e valores do meio ambiente. Londrina, PR: Eduel, 2012.

ZANIRATO, Sílvia Helena; ROTONDARO, Tatiana. Consumo, um dos dilemas da sustentabilidade. Estudos Avançados, São Paulo, v. 30, n. 88, p. 77-92, set./dez. 2016. Disponível em: <http://www.scielo.br/scielo. php?script=sci_arttext\&pid=S0103-40142016000300077>. Acesso em: 18 abr. 2017.

\section{Sobre as autoras:}

Elisa Ferrari Justulin Zacarias: Mestranda do Programa de Pós-Graduação em Ciências do Ambiente e Sustentabilidade na Amazônia (PPG-CASA) da Universidade Federal do Amazonas (UFAM). E-mail: elisa.justulin@gmail.com

Maria Inês Gasparetto Higuchi: Pesquisadora do Instituto Nacional de Pesquisas da Amazônia (INPA) e professora do Programa de Pós-graduação em Ciências do Ambiente e Sustentabilidade na Amazônia da Universidade Federal do Amazonas (UFAM). E-mail: higuchi.mig@gmail.com 
